\title{
Dramaturgia e Pós-Modernidade: a rapsódia como estratégia pós-moderna para o drama
}

\author{
João Alberto Lima Sanches \\ Universidade Federal do Recôncavo da Bahia - UFRB \\ Email: joaoright@gmail.com
}

$\mathrm{O}$ artigo discute estratégias de composição recorrentes nas dramaturgias contemporâneas, relacionando-as à noção de rapsódia, formulada pelo dramaturgo e teórico francês Jean-Pierre Sarrazac, e ao princípio de multiplicidade, abordado pelo escritor Ítalo Calvino no livro Seis Propostas para o próximo milênio. $\mathrm{O}$ artigo desenvolve uma associação entre multiplicidade, procedimentos rapsódicos de construção dramática e considerações sobre a pós-modernidade. Para isso, escritos do filósofo Jean-François Lyotard são utilizados como referência, e também a noção de princípio da pesquisadora e atriz Sônia Rangel.

Palavras-chave

Dramaturgia. Rapsódia. Pós-Modernidade.
The article focuses on some strategies of composition that are recurrent in contemporary dramaturgy and which can be related to the notion of rhapsody, formulated by the french playwright and theorist Jean-Pierre Sarrazac, and to the principle of multiplicity, approached by the writer Italo Calvino in the book Six proposals for the next millennium. The article develops an association between the principle of multiplicity, rhapsodic procedures of dramatic construction and considerations about postmodernity. Writings of the philosopher JeanFrançois Lyotard are used as reference, and also the notion of principle as discussed by the actress and researcher Sonia Rangel. Keywords

Dramaturgy. Rhapsody. Post-Modernity. 
Em seus estudos sobre processos de criação, a escritora, atriz e pesquisadora Sônia Rangel apresenta algumas noções que podem auxiliar na compreensão da invenção e da recepção de obras artísticas. Entre suas contribuições, destaquemos a noção de princípio. Segundo Rangel (2006), princípio é "[...] aquela unidade molecular que, ao ser retirada da obra e do seu pensamento, Ihe esvazia sentido, configuração, vitalidade" (Rangel, 2006, p. 312). Para a autora, um princípio difere de um conceito, uma vez que um conceito preexiste, precede a ação, tende a modelar o objeto. Já um princípio é da ordem do reconhecimento, organiza a existência de uma obra, está desatrelado de tempos, espaços, hierarquias, opera através da aproximação, da compreensão, da invenção. Rangel ainda afirma que a noção equivaleria ao que o escritor Ítalo Calvino (1990) defende em Seis Propostas para o Próximo Milênio, livro que reúne cinco conferências do autor, realizadas em Harvard, nas quais são abordadas cinco qualidades, ou cinco valores da criação literária - cinco princípios que o autor preconiza.

A última das propostas presentes no livro de Calvino se refere ao princípio de multiplicidade. Ao comentar obras de diferentes autores como Carlo Emilio Gadda, Robert Musil, Proust, Flaubert, Joyce, Eliot, Borges, entre outros, Calvino aborda a narrativa como "[...] enciclopédia, como método do conhecimento e, principalmente, como rede de conexões entre os fatos, entre as pessoas, entre as coisas do mundo" (Calvino, 1990, p. 121). Através de diversos exemplos de procedimentos, o autor comenta características de construções narrativas que estão relacionadas ao princípio da multiplicidade como: a superposição de diversos níveis de linguagem e significado (o que daria um caráter enciclopédico à obra); a consideração da presença simultânea de elementos heterogêneos na determinação dos eventos; o caráter inconclusivo das narrativas; a fragmentação dos discursos; a tendência às escritas breves; a obra como amostragem ficcional das infinitas possibilidades de narração, entre outros aspectos.

Alguém poderia objetar que quanto mais a obra tende para a multiplicidade dos possíveis mais se distancia daquele unicum que é o self de quem escreve, a sinceridade interior, a descoberta de sua própria verdade. Ao contrário, respondo, quem somos nós, quem é cada um de nós senão uma combinatória de experiências, de informações, de leituras, de imaginações? Cada vida é uma enciclopédia, uma biblioteca, um inventário de objetos, uma amostragem de estilos, onde tudo pode ser continuamente remexido e reordenado de todas as maneiras possíveis. (Calvino, 1990, p. 138).

\section{—_ Multiplicidade e pós-modernidade}

Atualmente, a multiplicidade de algumas estratégias recorrentes de escrita pode estar relacionada com perspectivas de pensamento que muitos estudiosos associam à pós-modernidade. Em seu livro $A$ condição pós-moderna (2011), lançado em 1979, o filósofo francês Jean-François Lyotard discute a legitimação do saber nas sociedades pós-industriais, abordando o fim das grandes narrativas, ou metarrelatos unificadores, que pretendiam explicar a existência de maneira totalizante. Esse questionamento dos discursos universalizantes, anunciado por Lyotard no final da década de 1970 , ainda hoje pode ser observado na tendência contemporânea em reconhecer o caráter múltiplo do mundo, do conhecimento e da- 
quilo que entendemos por identidade. Nesse contexto, outro tipo de legitimação do conhecimento se estabelece. Cada vez mais, o saber assume-se como provisório, parcial, aberto a indefinidas possibilidades de desenvolvimento. Isto se reflete tanto na temática quanto na estruturação das obras artísticas, em seus diferentes modos de construção poética.

Simplificando ao extremo, considera-se "pós-moderna" a incredulidade em relação aos metarrelatos. É, sem dúvida, um efeito do progresso das ciências; mas este progresso, por sua vez, a supõe. Ao desuso do dispositivo metanarrativo de legitimação corresponde sobretudo a crise da filosofia metafísica e a da instituição universitária que dela dependia. A função narrativa perde seus atores (functeurs), os grandes heróis, os grandes perigos e o grande objetivo. Ele se dispersa em nuvens de elementos de linguagem narrativos, mas também denotativos, prescritivos, descritivos etc., cada um veiculando consigo validades pragmáticas sui generis. Cada um de nós vive em muitas destas encruzilhadas. Não formamos combinações de linguagem necessariamente estáveis, e as propriedades destas por nós formadas não são necessariamente comunicáveis (Lyotard, 2011, p. xvi).

Lyotard também discorre, em diferentes textos, sobre como o pensamento pós-moderno se contrapõe ao ideal moderno que, segundo ele, seria historicista, "escatológico":

[...] através de inúmeros episódios, a modernidade leiga mantém esse dispositivo temporal, o de uma "grande narrativa", como se disse, que promete em seu termo a reconciliação do sujeito consigo mesmo e o fim de sua separação. Embora secularizadas, a narrativa das Luzes, a dialética romântica ou especulativa e a narrativa marxista exibem a mesma historicidade que o cristianismo, porque conservam o seu princípio escatológico. O remate da história, por mais que seja sempre adiado, restabelecerá uma relação plena e inteira com a lei de Deus no paraíso cristão, lei da Natureza no direito natural fantasiado por Rousseau, sociedade sem classes, antes da família, da propriedade e do Estado imaginada por Engels. É sempre um passado imemorial que se encontra prometido como fim último. É essencial ao imaginário moderno projetar sua legitimidade para a frente, ao mesmo tempo em que a fundamenta numa origem perdida. A escatologia reinvindica uma arqueologia. Esse círculo que também é o círculo hermenêutico, caracteriza a historicidade como imaginário moderno do tempo (Lyotard, 1996, p. 94).

A citação acima foi extraída do texto Uma fábula pós-moderna, que integra o livro Moralidades pós-modernas de Jean-François Lyotard (1996). No texto, Lyotard apresenta uma fábula cujo sujeito, a principal personagem, é a energia que movimenta e proporciona o desenvolvimento de tudo que há no universo: partículas, corpos, sistemas, vida e, consequentemente, o homem. Na narrativa, os seres humanos, depois de diversos estágios de desenvolvimento, estabelecem os sistemas liberais democráticos como os mais adequados às demandas de organização social, constituindo a ideia de progresso e induzindo a uma "[...] representação escatológica da história dos sistemas humanos" (Lyotard, 1996, p. 94). Essa "representação escatológica" se traduziria em historicidade, ou seja, numa crença, ou numa compreensão do tempo e da história como portadores de uma reconciliação do sujeito consigo mesmo, do fim de sua separação, da reintegração, ou do acesso ao sentido último da existência. Esta dimensão, no entanto, seria exclusivamente humana, e a narrativa apresentada por Lyotard não estabelece o homem como personagem principal, nem uma progressão causal e linear, pelo contrário, a fá- 
bula configura uma sucessão de acontecimentos definidos arbitrariamente, "[...] a partir de movimentos físicos supostamente uniformes e regulares" (Lyotard, 1996, p. 95). Ao fim da narrativa, os seres humanos estão tentando superar a destruição do Sol e, consequentemente, a civilização tal como se encontra.

A fábula não aponta para uma emancipação, ou esperança de salvação, pelo contrário, sugere que a humanidade deverá ser ultrapassada por outra formação mais complexa. Lyortard considera a fábula apresentada como pós-moderna - pois ela não ofereceria nenhum dos aspectos principais da historicidade, deixando o pensamento na expectativa da finalidade. Segundo o filósofo, seria justamente essa expectativa de finalidade o que caracterizaria "[...] o estado pós-moderno do pensamento, o que atualmente se convencionou chamar sua crise, seu mal-estar ou sua melancolia" (Lyotard, 1996, p. 97). Essa perspectiva que associa o pensamento pós-moderno à incredulidade em relação às narrativas unificadoras, ou à recusa às explicações totalizantes, tem ligação com a atitude afirmativa de valorização da multiplicidade. A tendência está presente na produção artística contemporânea de maneira geral, incluindo a dramaturgia e o teatro:

O período pós-moderno, escreve Jean François Lyotard em La condition postmoderne [A condição pós-moderna], anuncia o fim dos "grandes heróis, dos grandes perigos, dos grandes périplos e dos grandes objetivos". Ele analisa o fim das grandes narrativas como ligado à antiga preeminência da narração na formulação do saber tradicional [...] Ao passo que os dramaturgos clássicos retomavam as grandes narrativas fundadoras, míticas ou morais, reelaborando suas fontes na perspectiva de valores de suas sociedades, os dramaturgos pós-modernos e seus leitores "sabem que a legitimação só pode vir através de sua prática linguística", diz ainda Lyotard [...] O teatro ainda narra, mas cada vez menos de forma prescritiva e adesista. Os pontos de vista sobre a narrativa se multiplicam ou se dissolvem em enredos ambíguos (Ryngaert, 1998, p. 84-85).

A pós-modernidade tem seus desdobramentos em todas as áreas do conhecimento, da produção e da manutenção dos laços sociais. Como mostra a citação anterior, a dramaturgia e o teatro também são influenciados por esta crise dos grandes relatos. As ideias de Lyotard sobre o processo pós-moderno de legitimação do saber podem ajudar a compreender determinados modos de construção das dramaturgias contemporâneas que se identificam com o princípio da multiplicidade, abordado por Calvino (1990). Estratégias recorrentes da produção atual como a fragmentação das fábulas, a recusa a um sentido unívoco, a constante relativização dos discursos, a busca por efeitos de polifonia, a utilização de recursos metalinguísticos, entre outros, podem ser associadas tanto ao horizonte filosófico da condição pós-moderna quanto ao princípio (poético) da multiplicidade. Talvez, o correto seja afirmar que a multiplicidade é um princípio pós-moderno e que podemos reconhecê-lo em grande parte da produção dramatúrgica (e artística) contemporânea.

Rapsódia: uma estratégia pós-moderna para o drama?

A noção de rapsódia, formulada pelo dramaturgo e teórico Jean-Pierre Sarrazac em seu livro O futuro do drama (Sarrazac, 2002), é capaz de sintetizar uma série de estratégias de 
criação já mencionadas. A partir do estudo de autores europeus, em sua maioria franceses, como Bernard-Marie Koltés, Michel Vinaver, Armand Gatti, André Benedetto, mas também Brecht, Beckett, Pirandello, entre outros, Sarrazac aborda diversos procedimentos criativos os quais associa a uma pulsão rapsódica, a um gesto de autor-rapsodo. É possível reconhecer nesses procedimentos comentados por Sarrazac o princípio de multiplicidade e outras tantas qualidades que, baseando-nos em formulações de Lyotard, arriscamos adjetivar de pós-modernas.

Segundo Sarrazac (2002), estaria em desenvolvimento atualmente uma dramaturgia das passagens, do trânsito, dos limiares, onde todas as eventualidades da vida (reais, ou imaginárias) pudessem ser expostas simultaneamente.

A obra dramática encontra-se isenta da obrigação de seguir o encadeamento cronológico dos acontecimentos. Ela explora, numa abordagem diferencial e aleatória, as potencialidades de cada situação. Surge, então, um teatro dos possíveis, cuja primeira intuição remonta a Brecht, quando este inculcava nos actores a técnica do "não-antes-pelo-contrário" [...] Mas, aquilo que em Brecht estava ainda implícito torna-se hoje explícito. Assiste-se, no teatro de Gatti ou Benedetto, à radicalização e à transposição para o domínio da literatura de um método de trabalho característico do actor brechtiano (Sarrazac, 2002, p. 64-65).

Dramaturgo, professor e coordenador do Grupo de Pesquisas sobre o Drama da Universidade de Paris III, Sarrazac desenvolveu com seus colaboradores um olhar sobre a produção dramática contemporânea que dialoga com o teórico húngaro Peter Szondi (2011) e também com o linguista russo Mikhail Bakhtin (2010; 2011; 2013), atualizando-os para uma perspectiva menos canônica e menos teleológica do drama, na qual o interesse do estudo estaria voltado mais para as múltiplas e cambiantes conexões entre as formas dramáticas do que para uma explicação totalizadora, capaz de identificar um eixo comum a todas elas. Em vez do conceito de sujeito épico teorizado por Szondi, Sarrazac propõe a noção de autor-rapsodo. Em vez da emersão épica do drama, ou da romancização dos gêneros literários, Sarrazac percebe dinâmicas de transbordamentos constantes da forma dramática, e denomina rapsódia a esse devir contemporâneo do drama, seu olhar se concentra na pulsão rapsódica das escritas mais recentes.

No pósfacio do livro O futuro do drama (Sarrazac, 2002), resultado de sua tese de doutoramento, ao comentar a opção pela noção de rapsódia, Sarrazac cita a romancização vislumbrada por Bakhtin e a epicização proposta por Szondi e tantos teóricos marxistas. Sarrazac afirma que a romancização dos outros gêneros, de que fala Bakhtin, seria incontestável unicamente durante o período em que a arte do romance foi predominante e serviu de modelo. Esse período iria da segunda metade do século XVIII ao início do século XX, com um pico no momento naturalista. Sarrazac também comenta o preconceito bakhtiniano em relação ao dialogismo no drama, assim como a visão teleológica, implícita nos defensores marxistas da emersão épica. Defende, no entanto, a visão do épico formulada pelo teórico alemão Walter Benjamin:

Falar de rapsodização da obra teatral, detectar na escrita teatral uma pulsão rapsódica, é voltar à concepção ampla de épico de Benjamin. A esta ideia de "atalho de contrabando através do qual a herança do drama medieval e barroco chegou até nós". A pulsão rapsódica - que não signifi- 
ca nem abolição, nem neutralização do dramático (a insubstituível relação imediata entre si mesmo e o outro, o encontro, sempre catastrófico, com o Outro, que constituem privilégio do teatro) - procede, na verdade, por um jogo múltiplo de aposições e de oposições. Dos modos: dramático, lírico, épico e mesmo argumentativo. Dos tons ou daquilo a que chamammos "gêneros": farsesco e trágico, grotesco e patético, etc (Sarrazac, 2002, p. 227).

Embora a primeira edição em português de O futuro do drama seja de 2002, o livro refere-se a uma reflexão de Sarrazac sobre a produção dramática francesa, resultado de sua pesquisa de doutorado no final dos anos setenta. Em 1998, no entanto, o autor escreveu um posfácio para nova edição do livro, reafirmando a permanência de suas teses e de seu conceito de rapsódia. O trabalho continuou com a coordenação de seu grupo de pesquisa sobre o tema, cujo resultado mais recente foi publicado no Brasil em 2012: o Léxico do drama moderno e contemporâneo (SARRAZAC, 2012). A publicação, organizada e coescrita por Sarrazac, reúne 57 verbetes de autoria de variados pesquisadores do grupo, alguns bastante conhecidos dos leitores brasileiros como Jean-Pierre Ryngaert. Os verbetes do Léxico (SARRAZAC, 2012) comentam procedimentos, princípios e questões recorrentes nas dramaturgias contemporâneas a partir da contraposição dessas práticas aos conceitos de drama absoluto e de crise do drama de Peter Szondi (2011). Mas, ao retomar as ideias de Szondi e de toda a tradição crítica da qual ele faz parte, Sarrazac (2012) procede a uma reavaliação dessa tradição e, em relação a Szondi, especificamente, faz uma crítica direta à visão teleológica do autor, pró-epicização, que considerava a emersão do épico no drama como uma evolução, um progresso formal. Na abordagem de Szondi, autores como Ibsen, Strindberg e Tchekhov seriam experimentadores, cujo trabalho prepararia o teatro épico vindouro.

Em seu gesto sócioestético marxista, Szondi atribui aos grandes dramaturgos da virada do século o mesmo lugar e a mesma função no devir das formas teatrais que Cézanne e Wagner tiveram no das formas pictórias e musicais [...] Em suas análises dramatúrgicas, Szondi insiste mais, evidentemente, no que convém "deixar para trás" do que na paradoxal "perfeição" das obras de transição (Sarrazac, 2012, p.25).

Para exemplificar, Sarrazac critica três abordagens que Szondi faz, respectivamente, de Ibsen, Strindberg e Pirandello, no verbete inicial do Léxico, intitulado Introdução à crise do drama (Sarrazac, 2012). Sobre as peças de Ibsen, Szondi afirma que a fachada de peça bem-feita dissimularia a ausência de uma efetiva ação no presente. Para Sarrazac, a análise não leva em conta a evolução da dramaturgia de lbsen, como é evidente em sua última peça, Quando despertarmos de entre os mortos, que não corresponderia mais às regras da peça bem feita. A segunda crítica do autor se refere à análise que Szondi faz de Sonata de espectros de Strindberg, na qual, através da personagem Hummel, se veria o eu épico no palco, porém, ainda sob o "disfarce de um personagem de drama". Para Sarrazac, Szondi erra, duplamente, ao não compreender a clivagem da personagem e considerar um fracasso justamente o que torna a obra original: a maneira particular como Strindberg sintetiza elementos épicos, dramáticos e líricos em sua construção.

Por fim, um terceiro exemplo semelhante do preconceito de Szondi em favor do devir épico 
é comentado. Ao referir-se a Seis personagens à procura de um autor, de Pirandello, como uma crítica do drama, Szondi condena o dramaturgo, porque ele se recusaria a "destruir" totalmente a dimensão dramática, escolhendo um desfecho dramático para a peça. Para Sarrazac, mais uma vez, a constatação de Szondi não levaria em conta um particular tensionamento do dramático, do épico e do lírico, operado nessa obra metadramática de Pirandello, cuja espirituosa construção a tornou tão conhecida.

No essencial, trata-se - repetimos - de abandonar a ideia segundo a qual o horizonte - o fim - do teatro dramático poderia ter sido o teatro épico (como o do capitalismo deveria ser o comunismo). Para isso, não há necessidade alguma de se rejeitar o marxismo e, tampouco, a abordagem socioestética do teatro moderno e contempôraneo. Basta, ao contrário, interrogar-se sobre certas rejeições "ideológicas" de pensadores marxistas do teatro, não obstante bem diferentes uns dos outros, como Lukács, Brecht, Adorno, Szondi, e proceder a uma reavaliação dos objetos rejeitados: principalmente o "dramático" (não mediatizado pelo "épico") e seu corolário, a subjetividade, polemicamente rebatizada de "subjetivismo". Como se a manutenção da relação intersubjetiva e sobretudo o apelo ao intrassubjetivo, ao íntimo, tão presentes no teatro do século $X X$, de Strindberg a Adamov ou a Sara Kane, significassem inevitavelmente regressão ao individualismo, ao apolitismo, em suma, ao teatro "burguês" (Sarrazac, 2012, p. 30).

Em síntese, se os desvios de inclinação épica foram brilhantemete teorizados e preconizados no século XX, com o apoio e engajamento das ideologias de orientação marxista, Sarrazac parece reconhecer, na citação acima, certo preconceito teórico com a subjetividade ao qual o Léxico (Sarrazac, 2012) procuraria responder, entre outras questões. As obras de autores estudados por Sarrazac como Heiner Muller, Peter Handke, Michel Vinaver, Armand Gatti, Bernard-Marie Koltès, Sarah Kane, Edward Bond, entre outros, sem dúvida, encorajam o estudo de certas recorrências de procedimentos dramatúrgicos que podemos associar a uma emersão da subjetividade, à abordagem do inconsciente, do íntimo, ou, em nossos termos, à exploração de possibilidades líricas do drama. Isto não significa, contudo, negligência do grupo com as heranças épicas, pelo contrário. A evidência está na quantidade de menções à Brecht, presentes não apenas no Léxico (Sarrazac, 2012) como no O futuro do drama (Sarrazac, 2002) e também em $A$ fábula e o desvio (Sarrazac, 2013) publicações já traduzidas para o português. Dos 57 verbetes do Léxico, nenhum apresenta o adjetivo lírico em seu título e, em apenas oito, é possível associar diretamente o título a algum aspecto de subjetividade ou liricização: Coro/Coralidade; Íntimo; Jogo de sonho; Monodrama (polifônico); Monólogo; Oralidade; Poema dramático; Voz.

Ainda sobre a noção de rapsódia, é importante destacar que, apesar de sua abertura para as emersões líricas das dramaturgias modernas e contemporâneas, a noção estaria inicialmente ligada ao modo épico:

Através da figura emblemática do rapsodo, que se assemelha igualmente à do "costurador de lais" medieval reunindo o que previamente rasgou e despedaçando imediatamente o que acaba de juntar -, a noção de rapsódia aparece, portanto, ligada de saída ao domínio do épico: o dos cantos e da narração homéricos, ao mesmo tempo que a procedimentos de escrita tais como a montagem, a hibridização, a colagem, a coralidade. (Hersant; Naugrette, 2012, p. 152). 
Conceito transversal, que se desdobra em outras noções, a rapsódia é apresentada por Sarrazac (2002) como uma síntese de seu estudo das escritas dramáticas contemporâneas. Rapsódia é o nome de um devir múltiplo do drama que contraria a concepção organicista da Poética aristotélica, à qual Sarrazac denomina de "belo animal aristotélico". A expressão refere-se à comparação que Aristóteles faz, na Poética (Aristóteles, 1992), entre a fábula/intriga dramatúrgica e um ser vivo cuja beleza residiria na extensão e ordenação. A imagem do "belo animal" corresponde a uma concepção de fábula/intriga como totalidade ordenada, encadeamento lógico, completude, em síntese, corresponde aos conceitos aristotélicos de unidade, totalidade, causalidade e verossimiIhança.

Contra a "peça benfeita" [sic], último avatar do "belo animal" aristotélico, o devir rapsódico do teatro contemporâneo coloca em questão a própria ideia de composição: transformada em montagem de arquivos no teatro documentário de Weiss, justaposição de fragmentos narrativos e dramáticos em A missão de Muller, a escrita teatral obedece a uma lógica de decomposição. Nesse sentido, peças tão díspares como Roberto Zucco de Koltès, Hamlet-máquina de Muller, Imprécations [As imprecações] de Michel Deutsch ou Barba-azul, esperança das mulheres de Dea Loher desvelam-se como outras tantas variações em torno da morte do "belo animal". Morte incessantemente repetida, pois produtora de formas novas, em que a unidade constitui-se em trabalho do heterogêneo, da continuidade, da ruptura, da harmonia, da dissonância (Kuntz, 2012, p. 42-43).

A ideia de dramaturgias rapsódicas se refere, portanto, a construções híbridas, compostas por diferentes materiais, gêneros, vozes, articulando momentos dramáticos, épicos, líri- cos, argumentativos, entre outros possíveis. A noção tem uma ligação direta com as concepções brechtianas de montagem e gesto. A pulsão rapsódica, fluxo de costura e descostura, explicitaria o gesto da montagem que compõe os textos, colocaria o dramaturgo-rapsodo em primeiro plano, diferente da ideia tradicional de um autor dramático que procuraria "se esconder atrás das personagens", ou se ausentar do próprio texto. Nas dramaturgias atuais, seria frequente a explicitação da voz desse autor-rapsodo, através da qual é possível perceber um impulso questionador da soberania do ficcionamento.

Como exemplo, ao referir-se às obras do dramaturgo francês André Benedetto, Sarrazac (2002) sintetiza uma estratégia recorrente nas dramaturgias contemporâneas (e mesmo nas narrativas mencionadas por Calvino): "Impelida pela incessante meditação do autor sobre as personagens e sobre a fábula, a dramaturgia progride por hipóteses que se vão substituindo umas às outras, que se vão sucedendo sem nunca se anularem" (Sarrazac, 2002, p. 63). Nessa perspectiva, a dinâmica rapsódica corresponderia à estética do descontínuo, à preconização da irregularidade contra a uniformidade e a unidade, ao gosto pela fragmentação da fábula, aos efeitos de polifonia, à auto-referencialização constante, à desestabilização das noções tradicionais de personagem e diálogo, enfim, a uma série de transformações nas concepções tradicionais do drama que podem ser identificadas com princípios pós-modernos. 


\section{Considerações finais}

É controverso afirmar se temos, ou não, um novo paradigma de pensamento e cultura, se entramos mesmo num novo período histórico (a pós-modernidade). Não parece adequado adotar uma lógica historicista, paradoxalmente moderna, para compreender justamente o que seria o pensamento pós-moderno. Paralelamente, se a nossa época ainda evidencia uma incredulidade perante as grandes narrativas, se existe um apelo à multiplicidade e uma oposição às tentativas de totalização do sentido, não significa que não seja também evidente a continuidade dos ideais modernos de unidade, racionalidade e progresso.

O sociólogo polonês Zygmunt Bauman (2001), por exemplo, refere-se a uma modernidade líquida. Já o filósofo francês Gilles Lipovetsky (2004), refere-se a uma hipermodernidade. De maneiras bem distintas, os estudos de ambos os autores apontam para a permanência de alguns ideais modernos no desenvolvimento do que se convencionou chamar de pós-modernidade. Ou seja, existem muitos caminhos para pensar a criação artística atual, a escolha de alguns estudos sobre a pós-modernidade é operativa em determinados contextos, pois muitos fenômenos que são objetos de reflexão dos teóricos mencionados e muitos valores, qualidades, princípios identificados com a pós-modernidade podem auxiliar na reflexão sobre aspectos das produções artísticas atuais. Em relação à dramaturgia, destacamos no presente artigo o princípio da multiplicidade e, associando-o ao ideário pós-moderno, questionamos se a rapsódia poderia ser considerada uma estratégia pós-moderna para o drama. Esta provocação parte do reconhecimento da noção de rapsódia, for- mulada por Sarrazac (2002), como uma chave de leitura para diversas estratégias de criação que têm a multiplicidade como princípio, estratégias existentes desde sempre, mas particularmente recorrentes nas dramaturgias atuais e em grande parte das artes contemporâneas.

\section{Referências}

ARISTÓTELES. Poética. Tradução de Eudoro de Souza. São Paulo: Ars Poetica, 1992.

BAKHTIN, Mikhail. Estética da criação verbal. São Paulo: Martins Fontes, 2011.

. Problemas da poética de Dostoiévski. Rio de Janeiro: Forense Universitária, 2013.

. Questões de literatura e de estética: a teoria do romance. São Paulo: Hucitec, 2010.

BAUMAN, Zygmunt. Modernidade líquida. Rio de Janeiro: Zahar, 2001.

CALVINO, İtalo. Seis propostas para o próximo milênio. São Paulo: Companhia das Letras, 1990.

HERSANT, Céline; NAUGRETTE, Catherine. Rapsódia. In: SARRAZAC, Jean-Pierre et al. (Org.). Léxico do drama moderno e contemporâneo. São Paulo: Cosac Naify, 2012.

KUNTZ, Hélène. Belo animal (morte do). In: SARRAZAC, Jean-Pierre et al. (Org.). Léxico do drama moderno e contemporâneo. São Paulo: Cosac Naify, 2012.

LIPOVETSKY, Gilles. Os tempos hipermodernos. São Paulo: Editora Barcarolla, 2004.

LYOTARD, Jean-François. $A$ condição pós-moderna. Rio de Janeiro: José Olympio, 2011.

. Moralidades pós-modernas. São Paulo: Papirus, 1996. 
RANGEL, Sonia. Processos de criação: atividade de fronteira. In: CONGRESSO BRASILEIRO DE PESQUISA E PÓS-GRADUAÇÃO EM ARTES CÊNICAS, 4, 2006, Rio de Janeiro. Anais do IV Congresso Brasileiro de Pesquisa e Pós-Graduação em Artes Cênicas. Rio de Janeiro: 7Letras, 2006.

RYGAERT, Jean-Pierre. Ler o teatro contemporâneo. São Paulo: Martins Fontes, 1998.

SARRAZAC, Jean-Pierre et al. (Org.). Léxico do drama moderno e contemporâneo. São Paulo: Cosac Naify, 2012. . O futuro do drama. Porto: Campos das Letras, 2002. . Sobre a fábula e o desvio. Rio de Janeiro: 7Letras: Teatro do Pequeno Gesto, 2013.

SZONDI, Peter. Teoria do drama moderno (1880-1950). São Paulo: Cosac Naify, 2011.

Recebido: 25/06/2017

Aprovado: 02/09/2017 